\title{
Oral Discoid Lupus Erythematosus: A Case Effectively Managed and Differentiated with other Overlapping Diseases
}

\author{
Veena Naik ${ }^{1}$, Saurabh Prakash ${ }^{2}$ \\ ${ }^{1}$ Department of Oral Medicine and Diagnostic Radiology, Faculty of Dentistry, AIMST University, Semeling, Bedong, Kedah Darul \\ Aman, Malaysia, ${ }^{2}$ Department of Orthodontics, Orthodontics, Faculty of Dentistry, AIMST University, Semeling, Bedong, Kedah Darul \\ Aman, Malaysia
}

Email for correspondence: dr_veenasnaik@yahoo.co.in

\begin{abstract}
Discoid lupus erythematosus (DLE) is a benign disorder of the skin, most frequently involving the face, and characterized by well-defined red scaly patches of variable sizes, which heal with atrophy, scarring, and pigmentary changes, will have considerable effect on quality of life if untreated. Keeping the broad spectrum of red and white lesion in mind, here, we present a clinically diagnosed and successfully treated case of DLE, with differential diagnosis which might overlap the disease.
\end{abstract}

Key words: Autoimmune disease, discoid lupus erythematosus, systemic lupus erythematosus, triamcinolone acetonide

\section{INTRODUCTION}

Discoid lupus erythematosus (DLE) is a chronic skin condition of sores with inflammation and scarring involving the face, ears, and scalp and at times on the other body areas. The center areas may appear lighter in color with a rim darker than the normal skin and are defined as a chronic inflammatory condition of the skin, connective tissue, and specific internal organs that have associated circulating autoantibodies to DNA and other nuclear and RNA proteins; circular whitish buccomucosal lesions and erythematous rashes of sun-exposed skin..$^{[1-3]}$

In 460-370 BC, Hippocrates described these lesions as herpes esthiomenos, and then Rogerius gave the name "LUPUS." Biett in 1828 and Kaposi in 1872 were the first to describe LE. Monash in 1931 was first to describe oral lesions. ${ }^{[4]}$

\begin{tabular}{l|l|}
\hline Quick Response Code Article Info: \\
\hline doi: 10.5866/2017.9.10221 \\
$\begin{array}{l}\text { Received: } 07-11-2017 \\
\text { Revised: } 18-12-2017 \\
\text { Accepted: } 28-12-2017 \\
\text { Available Online: } 15-02-2018,2018 \text { (www. } \\
\text { nacd.in)@ NAD, 2018 - All rights reserved }\end{array}$ \\
\hline
\end{tabular}

There are two forms of lupus, DLE affecting the skin and mucous membranes, and SLE which may also affect joints, visceral organs, and other tissues. ${ }^{[5]}$ Hence, it can be classified into many forms. ${ }^{[6]}$

\section{CASE REPORT}

A 35-year-old male farmer by occupation reported to us with a complaint of wound and burning sensation in the lower lip for a month, which was insidious in onset, intermittent, localized, and severe in intensity, and aggravated on eating spicy food and on exposure to sunlight, then relieved on its own. He presented with the same complaint 2 years back, for that he was given medication, and he is unaware of the name of medicine. The patient was well built and nourished with his vital signs within normal limits. Extraorally, there are two components, one is erosion, which was seen on lower lip, extending from $1 \mathrm{~mm}$ away from left angle of mouth up to midline and superoinferiorly from vermilion zone to $2 \mathrm{~mm}$ above the lower lip line, with irregular borders, measuring about $1 \mathrm{~cm} \times 2 \mathrm{~cm}$, roughly oval in shape, surface was smooth. The other component was the pallor area around the erosion, which surrounded the erosive area [Figure 1]. On closure 
examination, the pallor component showed fine thin striae running from the erosive region peripherally. Solitary bilateral submandibular lymph nodes were palpable, enlarged, mobile, and tender. Intraorally, there is no evidence of lesion on the right and left buccal mucosa [Figures 2 and 3], generalized marginal gingival inflammation was noted. Based on history and clinical features, we considered working diagnosis as DLE involving lower lip with the following differential diagnosis (a) erosive lichen planus (ELP), (b) erythema multiforme (EM), (c) pemphigus vulgaris (PV), and (d) actinic cheilitis.

The patient was subjected to blood investigation (report of blood investigation formulated in

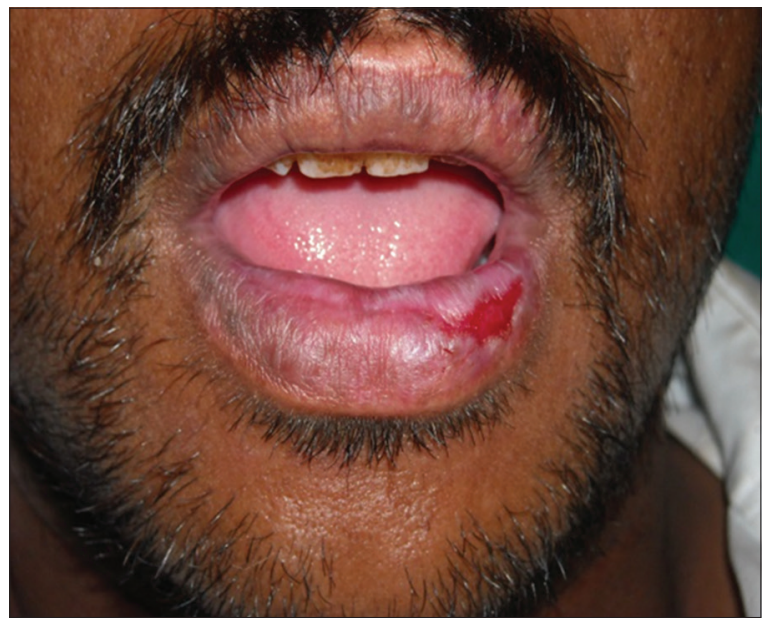

Figure 1: Clinical picture showing erosion on lower lip extending from $1 \mathrm{~mm}$ away from left angle of mouth up to midline and superoinferiorly from vermilion zone to $2 \mathrm{~mm}$ above the lower lip line

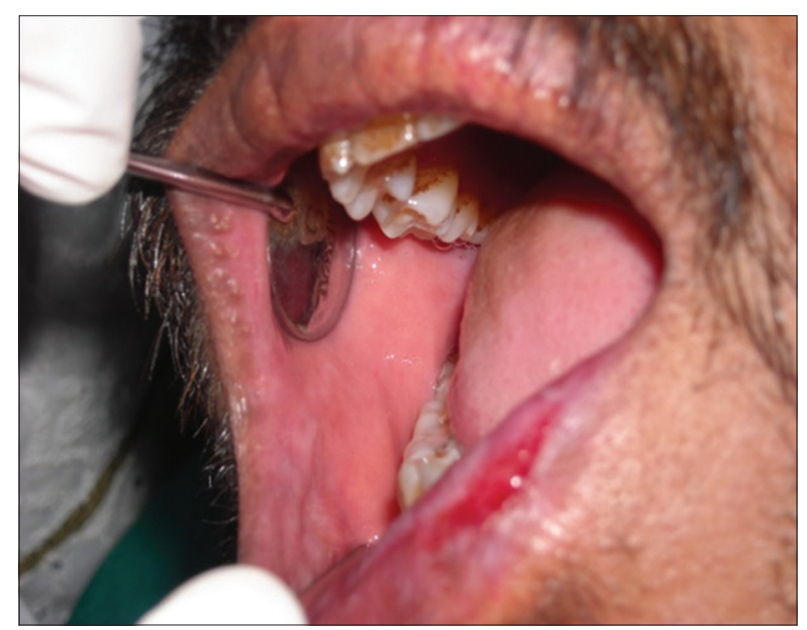

Figure 2: Intraorally, the right buccal mucosa shows absence of extension of lesion
Table 1), and biopsy report [Figure 4] suggestive of hyperkeratosis, atrophy of the epidermis, follicular plugging, liquefaction degeneration of the basal cell layer, edema, dilatation of small blood vessels, and perifollicular inflammatory infiltrate, confirming our diagnoses DLE.

The patient was treated with topical application of triamcinolone acetonide $0.1 \%$ (Tess oral paste) thrice daily for a week which was then tapered to twice daily as the lesion found to be subsiding. The patient was advised to avoid direct contact with sunlight, was also advised for oral prophylaxis on the healing of lesion. Within 15 days, the lesion healed [Figure 5]; later, the patient was followed up for a year and found no recurrence.

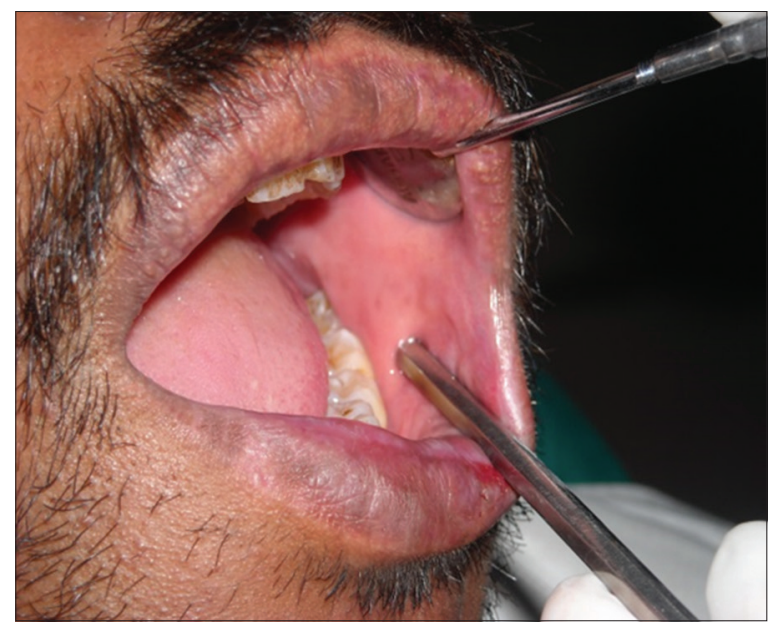

Figure 3: Intraorally, the left buccal mucosa shows absence of extension of lesion

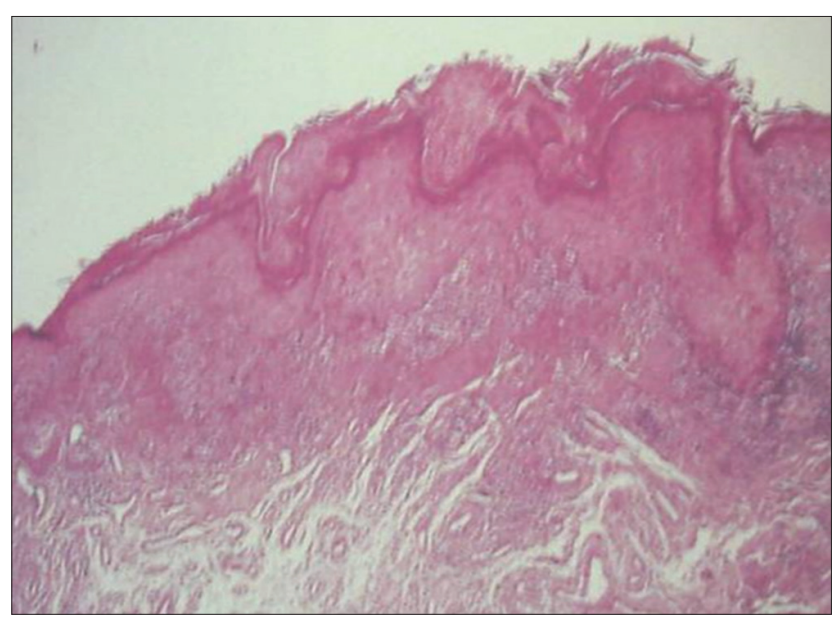

Figure 4: $\mathrm{H}$ and E section shows hyperkeratosis and atrophy of the epidermis 


\section{DISCUSSION}

$\mathrm{LE}$ is an autoimmune disease among other connective tissue diseases such as scleroderma, rheumatoid arthritis, polymyositis, and mixed connective tissue disease. Within the spectrum of diseases included in $\mathrm{LE}$, at one end is a disease confined mainly to the skin and mucosa and referred to as DLE and at the other end is a florid disease with systemic involvement of heart, lungs, brain, kidneys, and other organs called SLE. Epidemiology is charted below (Chart 1). According to Rothfield et al. and Hough, the age range for onset of disease was 21-40 years. The maximum patients (66.66\%) were observed between the age range of $26-45$ years..$^{[7-9]}$ Davis and Marks (1977) reported the female-to-male ratio to be 4:1, Anderson (1980) and Schiodt et al. studied oral DLE and found the female:male ratio of 4:1 and 50:1, respectively. However, some studies observed male predilection. ${ }^{[10]}$ Schiodt et al. also observed that oral DLE was most often seen on the buccal mucosa, gingiva, labial mucosa, and vermilion border. ${ }^{[9]}$ It

\begin{tabular}{lc} 
Table 1: Blood investigations result \\
Test & Range \\
\hline $\mathrm{Hb}$ & $14.6 \mathrm{~g} \%$ \\
$\mathrm{TLC}$ & $5100 \mathrm{cells} / \mathrm{mm}^{3}$ \\
$\mathrm{DLC}$ - neutrophils & 58 \\
Lymphocytes & 36 \\
Eosinophils & 04 \\
Monocytes & 02 \\
ESR & $22 \mathrm{~mm} / \mathrm{h}$ \\
PCV & 31 \\
\hline
\end{tabular}

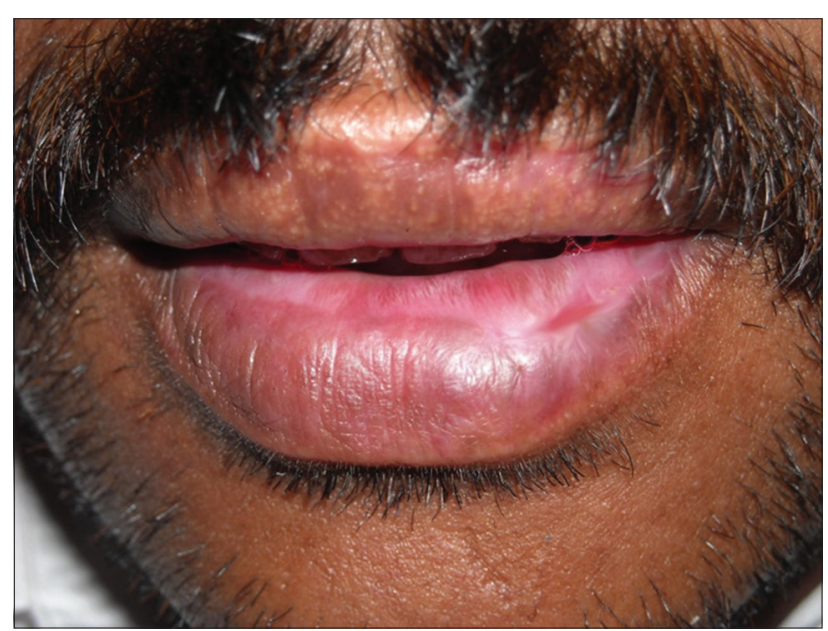

Figure 5: Post-treatment clinical picture showing resolution of lesion within 15 days of treatment is caused by interplay of genetics, hormonal, and environmental factors. $1-5 \%$ of patients with discoid lupus may develop systemic LE and $25 \%$ of patients with SLE may develop typical chronic discoid lesions at some time during their illness. ${ }^{[11]}$ The oral cavity is involved in $20 \%$ of DLE patients. ${ }^{[12]}$ Different studies of oral lesions in the course of LE have shown a frequency varying from $9 \%$ to $45 \%$ in systemic disease and $3-20 \%$ in localized cutaneous disease. ${ }^{[13]}$

\section{Clinical features}

Clinical presentations of oral LE lesions have been tabulated in Table 2. ${ }^{[14]}$

Early lesions have mucosal hemorrhage, erosion, and superficial erythematous patches with dilated blood vessels on the borders. The center is depressed or superficially ulcerated. Chronic lesions are well defined and circular, oval, or irregular in shape. Often, they have an elevated erythematous border. The center of the lesion is usually depressed, as seen in our case.

Differential diagnosis of labial lesions:

- ELP: A reticular pattern is more prominent, whereas in DLE striae appear very faint and fine. ELP is more symmetrically and widely distributed.

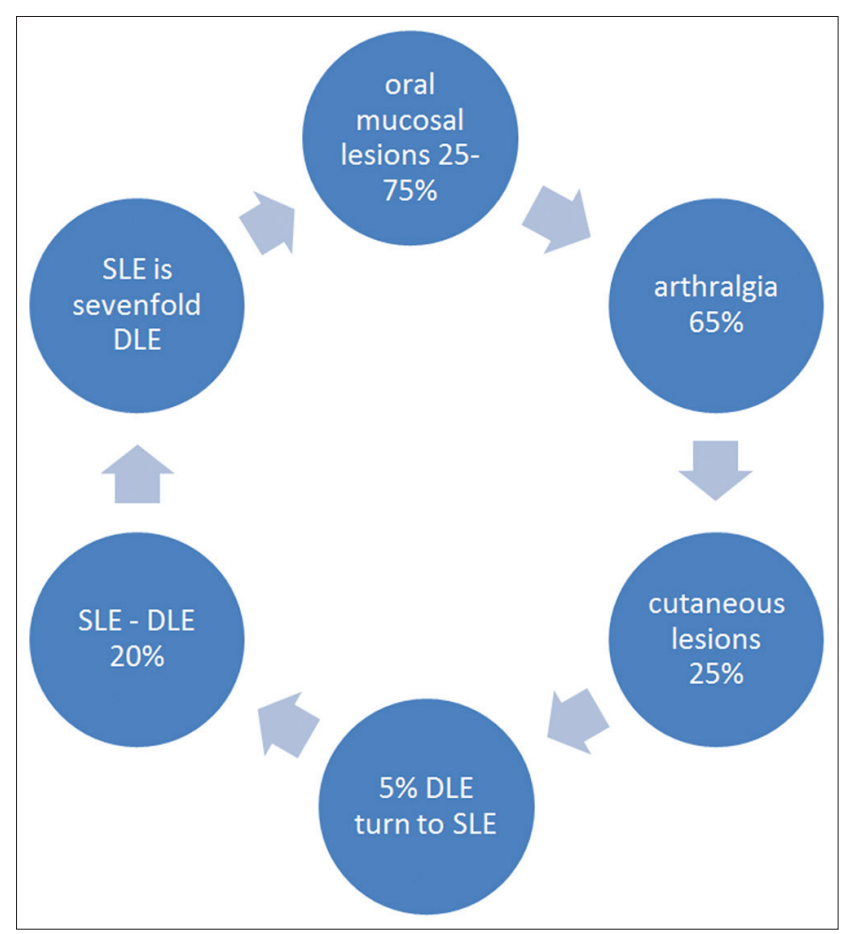

Chart 1: Epidemiology of lupus erythematosus 
Table 2: Clinical features of DLE

\begin{tabular}{lll} 
Chronic lesions: Discoid lesions & Subacute lesions & Acute lesions \\
\hline $\begin{array}{l}\text { Note - lesions are almost always asymmetrically } \\
\text { distributed on buccal cavity }\end{array}$ & $\begin{array}{l}\text { Discrete red patches, (much rarer } \\
\text { and more discrete than cutaneous }\end{array}$ & $\begin{array}{c}\text { Erythematopurpuric macules } \\
\text { Palatal erythema }\end{array}$ \\
$\begin{array}{l}\text { Atrophic or ulcerated round lesions with } \\
\text { peripheral keratotic radiating striae }\end{array}$ & $\begin{array}{l}\text { Pubacute LE) } \\
\text { Diffusely scaly labial patches }\end{array}$ \\
Linear ulcers with keratotic striae & & Ulcerations \\
"Honeycomb plaques" (longstanding scarring & & Bullous LE: Labial blisters \\
lesions) & & Intraoral intact or ruptured \\
Intensely keratotic lesions (verrucous LE) & & blisters \\
Palatal discoid lesions & & \\
Labial discoid lesions & & \\
Squamous cell carcinoma may arise in & & \\
long-standing scarring lesions & & \\
\hline
\end{tabular}

- EM: Involves anterior part of the mouth but has acute eruption and bleeding and scabs seen. Proceeded by vesicle or a bullae formation.

- PV: More extensive involves the whole of the oral cavity, tissue tags present along with ulcers. Proceeded by vesicle or a bullae formation.

- Herpes stomatitis: Prodromal symptoms present, vesicle formation present which is absent in DLE.

- Fixed drug eruption: Reaction to a particular drug, extensive lesion.

- Actinic cheilitis: Farmers lip appears more like a scab, striae absent.

Neoplastic change: $3.6 \%$ of long-standing DLE scars can turn into squamous cell carcinoma and $0.5 \%$ to basal cell carcinoma.

\section{Investigations}

The anti-Ro (SS-A) antibody is arguably the most important antibody determination except for antinuclear antibodies in an evaluation of patients suspected of having LE.

A histopathological distinction between acute, subacute, and chronic cutaneous LE lies in the intensity of epithelial affection, the severity of follicular damage, nature, and level of the inflammatory infiltrate in the dermis. Epithelium shows hyperkeratosis, granulosis, acanthosis and atrophy, spongiosis, hydropic degeneration (patchy or widespread), colloid bodies, and hyperproliferation of basal layer, sometimes with a presence of atypical keratinocytes. Edema, vasodilatation, with predominantly a lymphocytic infiltration in a perivascular orientation. ${ }^{[11,15]}$

DIF studies are often performed when diagnosing cutaneous and mucosal lesions of
LE. These are particularly useful in differential diagnosis between LE and other possibly similar clinical and histopathological conditions such as LP. The three major classes of immunoglobulins IgG, IgA, and IgM, as well as complement components may be found in basement membrane zone deposits of cutaneous and oral LE, in a linear and/or granular pattern. ${ }^{[12,16]}$

Management of oral lesions:

Oral therapy includes:

- Warned against excessive exposure to sunlight, ultraviolet light and heat

- Wear a broad-brimmed hat

- Sunscreen cream or lotion to applied regularly

- In a study, it is stated that fluocinonide $0.05 \%$ cream (a potent topical corticosteroid) appeared to be better than hydrocortisone $1 \%$ cream (a mild corticosteroid $)^{[17]}$

- Oral prednisolone $0.5 \mathrm{mg} / \mathrm{kg}$ rapidly tapered over 6 weeks

- Hydroxychloroquine, initially $200 \mathrm{mg}$ twice daily, reducing to $200 \mathrm{mg} /$ day after response

- Oral thalidomide has been tried for cases not responding to steroids and antimalarial drugs.

Topical steroid is the first-line drug for localized cutaneous and mucosal lesions. More recently, biological therapies with agents such as etanercept and tumor necrosis factor have demonstrated an overall decline in the disease activity. Efalizumab, a monoclonal antibody and a T-cell modulator, has also shown a good response in patients with DLE. ${ }^{[18]}$ Studies have reported inefficiency and side effects with topical steroids or antimalarials and confirmed promising results with topical tacrolimus ointment. ${ }^{[19,20]}$ Whereas, the present case showed 
effective results with topical steroids and no side effects for a span of year and half.

In the present case, the lesion on the lip was long standing and clinical picture both clearly indicated that the lesion is chronic DLE, which was further confirmed with the biopsy report. When compared to other lesions as discussed in the differentials, there will differences and difficulties concerning mostly the anatomic and functional peculiarities of oral tissues; hence, these limitations make it mandatory for clinical-pathological criteria to differentiate oral LE from other possibly similar conditions.

Further, the treatment with topical steroids also indicates the accurate diagnosis to which the patient responded well. Thus, the dentist may be in an important position to establish the diagnosis with the aid of clinical and histopathological findings before the cutaneous lesions become apparent.

\section{CONCLUSION}

Orallesionsmaybethefirstclinicalmanifestation of DLE. It is especially important for the dentist to recognize not only that some dermatoses exhibit concomitant lesions of the oral mucous membranes but also that manifestation of some diseases may be preceded by oral lesions. As DLE has varied clinical features and it resembles lichen planus, a careful diagnosis and investigation has to be carried out, and at the same time, precautions have to be taken about the side effect of the antimalarial drugs when treating these patients. This promotes resolution of established lesions and prevents scarring of skin lesions and also eases discomfort of the patients.

\section{REFERENCES}

1. Panjwani S. Early diagnosis and treatment of discoid lupus erythematosus. J Am Board Fam Med 2009;22:206-13.

2. William J, Timothy B, Dirk E. Andrew's Diseases of the Skin: Clinical Dermatology $10^{\text {th }}$ ed., Ch. 8. Philadelphia, PA: Saunders; 2005

3. Reedberg IM, Elsen AZ, Goldsmith LA, Katz SI. Fitzpatrick's Dermatology in General Medicine. $6^{\text {th }}$ ed., Vol 1 and 2. New York: Medical Publishing Division; 2003.

4. Ranginwala AM, Chalishazar MM, Panja P, Buddhdev KP, Kale HM. Oral discoid lupus erythematosus: A study of twenty-one cases. J Oral Maxillofac Pathol 2012;16:368-73.

5. Schiodt M. Oral manifestations of lupus erythematosus. Int J Oral Surg 1984;13:101-47.

6. De Rossi SS, Glick M. Lupus erythematosus: Considerations for dentistry. J Am Dent Assoc 1998;129:330-9.

7. Rothfield N, March C, Miescher P, McEwen C. Chronic discoid lupus erythematosus-A study of 65 patients and 65 controls. N Engl J Med 1963;269:1156-61.

8. Hough W. Discoid lupus erythematosus - A study of sex and age at onset. Acta Derm Venereol 1966;46:240-1.

9. Schiodt M, Halberg P, Hentzer B. A clinical study of 32 patients with oral discoid lupus erythematosus. Int $\mathrm{J}$ Oral Surg 1978;7:85-94

10. Sreejan CK, Gopakumar R, Babu S, Roopashri RK. Discoid lupus erythematosus: A case report with review of the literature. J Ind Acad Oral Med Rad 2009;21:37-41.

11. Kranti K, Seshan H, Juliet J. Discoid lupus erythematosus involving gingiva. J Indian Soc Periodontol 2012;16:126-8.

12. Serpico R, Pannone G, Santoro A, Mezza E, Piccolo S, Esposito V, et al. Report of a case of discoid lupus erythematosus localised to the oral cavity: Immunofluorescence findings. Int $J$ Immunopathol Pharmacol 2007;20:651-3.

13. Tuffanelli D, Dubois E. Cutaneous manifestations of systemic lupus erythematosus. Arch Dermatol 1964;90:377-86.

14. Nico MM, Vilela MA, Rivitti EA, Lourenço SV. Oral lesions in lupus erythematosus: Correlation with cutaneous lesions. Eur J Dermatol 2008;18:376-81.

15. Shklar G, Meyer I. The histopathology and histochemistry of dermatologic lesions in the mouth. Oral Surg 1961;14:1069-84.

16. Fitzpatrick TB, Johnson RA, Klaus W, Suurmond D. In: Colour Atlas and Synopsis of Clinical Dermatology. $4^{\text {th }}$ ed New York (NY): McGraw-Hill Companies; 2001. p. 368-9.

17. Jessop S, Whitelaw DA, Delamere FM. Drugs for discoid lupus erythematosus. Cochrane Database Syst Rev2009;4:CD002954.

18. Usmani N, Goodfield M. Efalizumab in the treatment of discoid lupus erythematosus. Arch Dermatol 2007;143:873-7.

19. Walker SL, Kirby B, Chalmers RJ. The effect of topical tacrolimus on severe recalcitrant chronic discoidlupus erythematosus. Br J Dermatol 2002;147:405-6.

20. Han YW, Kim HO, Park SH, Park YM. Four cases of facial discoid lupus erythematosus successfully treated with topical pimecrolimus or tacrolimus. Ann Dermatol 2010;22:307-11. 